\title{
Multiple sclerosis: patients' information sources and needs on disease symptoms and management
}

This article was published in the following Dove Press journal:

Patient Preference and Adherence

12 June 2010

Number of times this article has been viewed

\section{Albert I Matti' \\ Helen $\mathrm{McCarl}^{2}$ \\ Pamela Klaer ${ }^{2}$ \\ Miriam C Keane \\ Celia S Chen' \\ 'Department of Ophthalmology, Flinders Medical Centre and Flinders University, Bedford Park, SA, Australia; \\ ${ }^{2}$ The Multiple Sclerosis Society of South Australia and Northern Territory, Klemzig, SA, Australia}

Correspondence: Celia Chen Department of Ophthalmology, Flinders Medical Centre and Flinders University, Flinders Drive, Bedford Park, SA 5042, Australia

Tel +6I 882044899

Fax +6I 882770899

Email celia.chen@health.sa.gov.au
Objective: To investigate the current information sources of patients with multiple sclerosis (MS) in the early stages of their disease and to identify patients' preferred source of information. The relative amounts of information from the different sources were also compared.

Methods: Participants at a newly diagnosed information session organized by the Multiple Sclerosis Society of South Australia were invited to complete a questionnaire. Participants were asked to rate on a visual analog scale how much information they had received about MS and optic neuritis from different information sources and how much information they would like to receive from each of the sources.

Results: A close to ideal amount of information is being provided by the MS society and MS specialist nurses. There is a clear deficit between what information patients are currently receiving and the amount of information they actually want from various sources. Patients wish to receive significantly more information from treating general practitioners, eye specialists, neurologists, and education sessions. Patients have identified less than adequate information received on optic neuritis from all sources.

Conclusion: This study noted a clear information deficit regarding MS from all sources. This information deficit is more pronounced in relation to optic neuritis and needs to be addressed in the future.

Practice implications: More patient information and counselling needs to be provided to MS patients even at early stages of their disease, especially in relation to management of disease relapse.

Keywords: information sources, information needs, MS patients, optic neuritis

\section{Introduction}

Patient empowerment is the key to successful management of chronic diseases such as multiple sclerosis (MS). Information regarding disease relapse and the management options available is increasingly recognized as a crucial factor in patient empowerment with the advantages of better patient compliance and greater satisfaction with the health care provider, which translates into an increase in the quality adjusted life years experienced by the MS sufferer. ${ }^{1}$

There is a significant gap between the information received and the information required by patients with multiple sclerosis, and patients have expressed a consistent desire for more access to reliable information sources regarding symptoms, management, access to health care professionals, and rehabilitation. ${ }^{2-4}$ This information need, defined as a need for general information about the disease, its management, and prognosis, has been shown to be universal ${ }^{3}$ and desired throughout various stages 
of the course of MS. ${ }^{2}$ However patients in early stages of disease onset have been identified to have an even greater need for information. ${ }^{2}$

Specific areas of information need have been identified, including information regarding symptom alleviation and management. This is due to a prominent feature of MS being the relapsing and remitting nature, with new symptoms occurring such as loss of vision due to optic neuritis. ${ }^{5,6}$ This often leads to heightened anxiety and information on management of new symptoms has been generally lacking.,

It is important to understand the views of people with MS in regards to their understanding of their disease and the management options available to them, especially in the early stages of their disease so that health care providers can offer adequate support which is responsive to patients' needs. There is limited information about where patients are currently receiving their information and where they would like to acquire such knowledge.

This study aims to investigate the current information sources of patients with MS on disease symptom and management and to identify patient's preferred sources of information.

\section{Methods}

Patients newly enrolled with the Multiple Sclerosis Society of South Australia and Northern Territory, from 1/7/08 to 31/3/09, were invited to a 'Newly Diagnosed Multiple Sclerosis Education Evening'. Sixty newly diagnosed patients were invited and 30 attended the session. Participants were asked to complete a questionnaire rating how much information they had received about MS and optic neuritis from different information sources. The information sources incorporated into the questionnaire included neurologist, eye specialist, general practitioners, MS Society, education sessions, MS specialist nurse, friends, Internet, and other sources. Patients were asked to rate these information sources on a scale from 0 to 7 with 0 being no information has been provided, 4 being adequate information, and 7 being ideal information received. Participants were also asked how much information they wished to receive from each of these information sources. Questions relating to demographic information were also included, as were questions requiring participants to indicate whether they believed certain symptoms to be indicative of optic neuritis and whether they plan to develop an action plan to deal with optic neuritis in the future.

Wilcoxon signed rank tests were used to analyse the differences between the amount of information desired and the current information received by each provider. A $P$-value less than 0.05 was considered significant.
Optic neuritis is used as a model to examine how much information a person currently receives regarding management of new symptoms because optic neuritis is a prominent feature of MS relapse and more than half of people with MS have experienced at least one episode of optic neuritis during their disease. ${ }^{9}$ Participants were asked whether they previously had optic neuritis and their ability to recognize symptoms and signs of an optic neuritis episode were ascertained.

All participants consented to taking part in the study. The study was approved by the Flinders Clinical Research Ethics Committee.

\section{Results}

A total of 23 participants completed the study with an overall response rate of $77 \%$. The majority $(83 \%)$ of participants were aged between $31-60$ years of age (17\% were between 15-30 years, 44\% were between 31-45 years, and 39\% were between $46-60$ years) and all participants were within 4-8 months of MS diagnosis.

\section{How much information did patients receive about MS from different sources?}

Patients identified the MS Society and MS specialist nurses as providing almost ideal amounts of information regarding MS, with mean ratings of $6 \pm 1.73$ and $5.89 \pm 2.27$ respectively. Adequate levels of information were provided by neurologists $(\mathrm{m}=4.81 \pm 2.13)$ and was obtained from the Internet $(\mathrm{m}=4.06 \pm 2.04)$. Eye specialists, general practitioners (GPs), education sessions, friends, and other sources provided less than adequate information about MS (rate $<4$ ), (Figure 1). GPs and friends provided the least amount of information.

\section{How much information do patients wish to receive from each information resource?}

Patients wished to receive more information than they did from all sources except friends (Figure 2). Patients have identified the MS Society $(\mathrm{m}=6.47 \pm 0.91)$ and MS specialist nurses $(m=6.44 \pm 0.71)$ as the sources from which they would like to receive most information regarding MS (Figure 2). Information was least sought after from 'other' sources $(\mathrm{m}=2.67 \pm 3.28)$ and from friends $(\mathrm{m}=1.46 \pm 1.76)$.

Using Wilcoxin signed rank tests, four sources of information (neurologists, eye specialists, GPs, and education sessions) were identified for which patients reported a significant difference between the levels of information they were currently receiving and that which they would like to receive. 


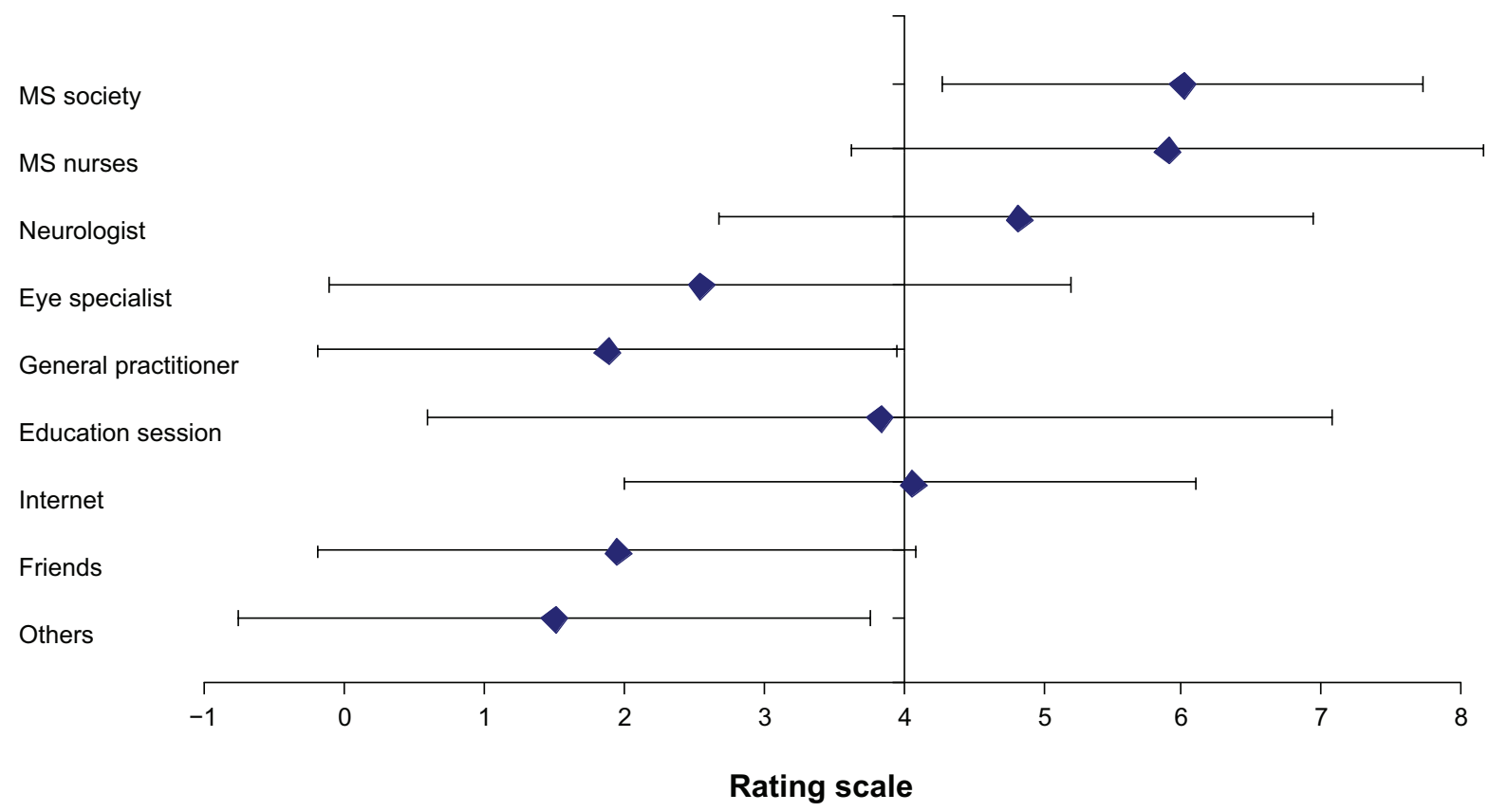

Figure I Patient rating of the amount of information they received from each of these sources about multiple sclerosis.

For the two most pronounced of these, GPs and eye specialists, there were large effect sizes and the median scores on the current information measure $(\mathrm{MdC})$ were below adequate while those on the desired $(\mathrm{MdD})$ were much higher (GPs: $\mathrm{z}=-3.07, P=0.002, \mathrm{r}=0.54, \mathrm{MdC}=1.5, \mathrm{MdD}=5$; eye specialists: $\mathrm{z}=-2.53, P=0.012, \mathrm{r}=0.50, \mathrm{MdC}=2, \mathrm{MdD}=7$ ). The results for neurologists and education sessions, while significant $(P=0.014, P=0.016$, respectively), showed smaller effect sizes ( $\mathrm{r}=0.39, \mathrm{r}=0.47$, respectively) and less clinically relevant changes in median scores $(\mathrm{MdC}=5, \mathrm{MdD}=7$ and $\mathrm{MdC}=6, \mathrm{MdD}=7$, respectively).

\section{How much information did patients receive about optic neuritis from different sources?}

Of the participants surveyed, $70 \%$ had heard of the term optic neuritis before the education session and $52 \%$ had either had optic neuritis in the past or knew someone who had. All information sources were given a mean score of less than 4 with regards to optic neuritis (ie, less than adequate information provided). Optic neuritis information was best provided by neurologists, eye specialists, and MS specialist nurses (Figure 3). Information was least adequately provided by GPs, friends, and other sources. None of the participants had a current plan of what to do or who to contact in the event of an acute optic neuritis but almost half indicated that they definitely intended to develop one following the education session, while a further $30 \%$ indicated they would consider it.

\section{Discussion}

This study reports on the current, actual, and desired information needs of MS patients in the early stages of their disease. Participants have identified that they receive most information from the MS Society and MS nurses. There are four sources where a significant gap is present between the amount of information participants currently received and how much they wish to receive. These four sources are general practitioners, eye specialists, neurologists, and education sessions.

In this study, the MS Society was the highest rated current provider of patient information and was also the highest rated desired information provider. This is in agreement with a previous study, which reported that most newly diagnosed MS patients contacted the MS Society for information. ${ }^{10}$ Although the MS Society is providing good information in regards to $\mathrm{MS}$ in general, more information is desired in regards to MS symptoms, prognosis, and management.

Our findings were also in agreement with similar results from a study by Somerset et $\mathrm{al}^{1}$ in which MS nurses were identified by a third of respondents as the professional with whom they would most like to have contact ${ }^{4,11}$ and acknowledged as an important current source of information for patients in the early stages of their disease.

In our study, participants report GPs to be providing less than adequate information on MS and optic neuritis ( $\mathrm{m}=1.88 \pm 2$ and $\mathrm{m}=0.93 \pm 1.0$, respectively). The GPs are identified as a source from which patients wish to receive significantly more information. This contrasts with a 2001 


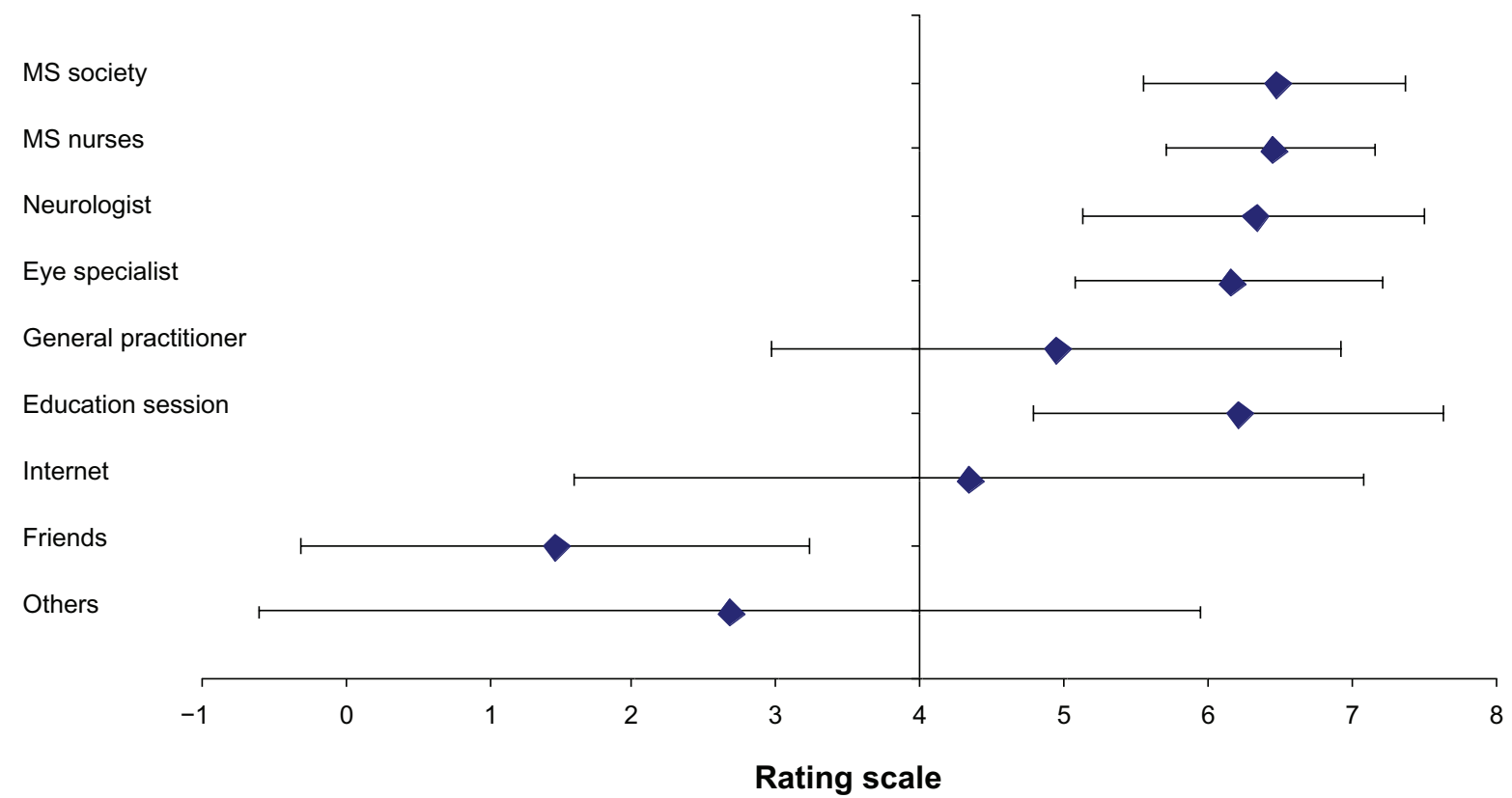

Figure 2 Patient rating of the amount of information they wish to receive from each of these sources about multiple sclerosis.

study, ${ }^{4}$ in which GPs were the most frequently consulted health professional by MS patients (78\%) and $87 \%$ of consultations were rated as helpful.

This study noted an important feature that information on symptom recognition and management in the event of an MS relapse are not adequately addressed at present. This is similar to the finding by Box et $\mathrm{al}^{7}$ that the biggest gap in information need related to the management of symptoms. This study found that only $8 \%$ of patients received information about how to manage new or unusual symptoms (ie, a relapse, including optic neuritis) and $66 \%$ would have liked information on this.? The mean score for information provided about optic neuritis was less than 4 (adequate) for all sources, suggesting that steps need to be taken to improve this. Closing this gap of a lack of patient information on optic neuritis is important given vision is an important quality of life indicator. The fact that patients with optic neuritis tend to be younger and are more likely to experience symptoms for a number of years if appropriate treatment is not provided also impacts on the significance of this.

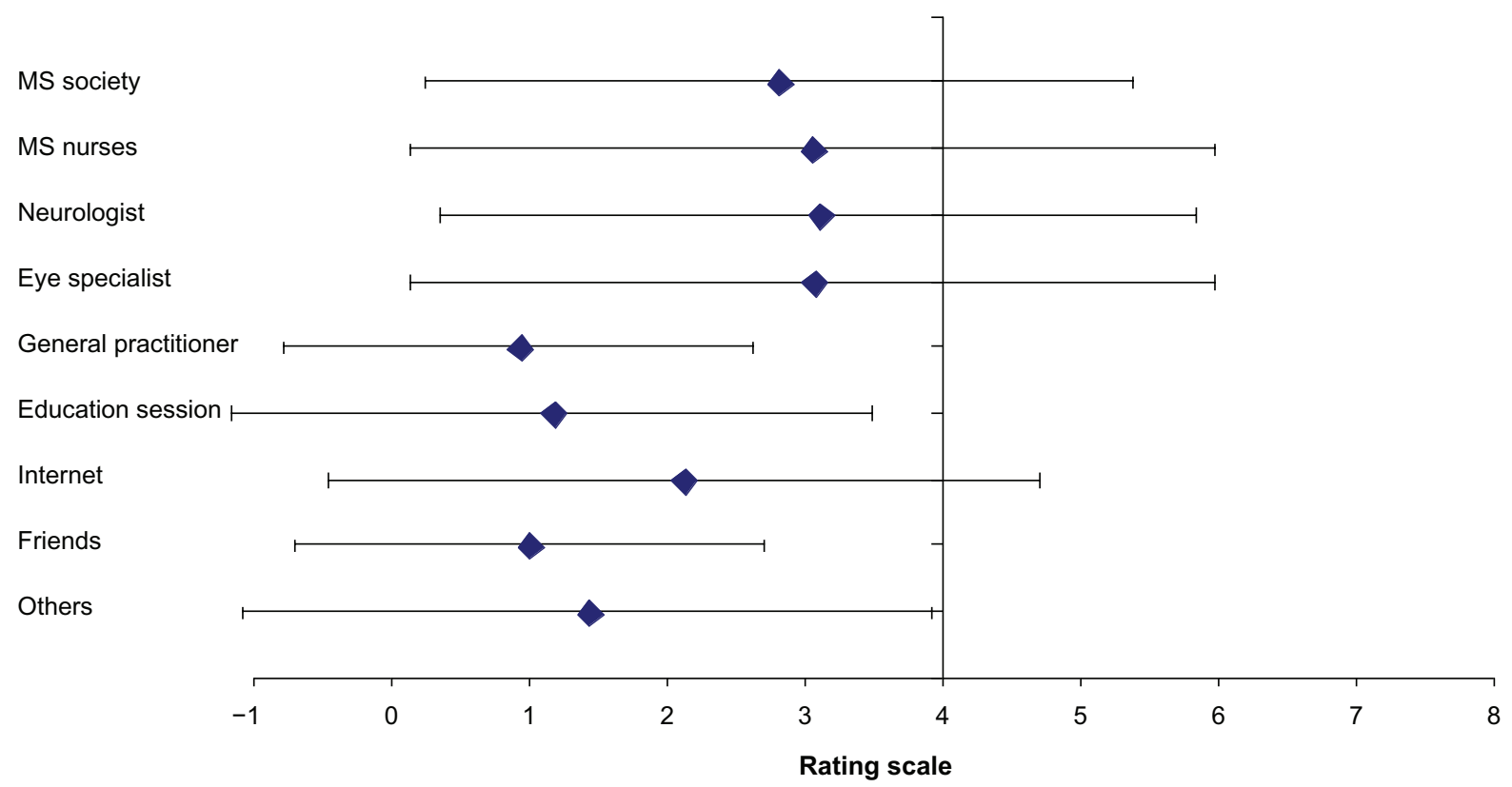

Figure 3 Patient rating of the amount of information they received from each of these sources about optic neuritis. 
There are several limitations associated with the current study. The majority of the population included in this study were aged between 30 and 60 years and only $17 \%$ were aged between 15-30 years. This may result in a bias of reporting in this study because the population may not represent the younger population who may have a different preference to information sources, such as from the Internet, over traditional methods of information transfer from physicianpatient contact. However despite an older population, we find a large variation in preferences, as indicated by the large standard deviation. This highlights the need to develop a more individualized approach to information provision depending on a patient's own experience of the disease. Recruitment of patients via the MS Society may have had a biasing effect on scores relating to this information source, with all those involved likely to have received some information from them. Another limitation of the study is that only the most highly motivated patients attended the session, which may influence the information needs reported. Patients may also go through various emotional stages when newly diagnosed with MS, such as denial and grief, before acceptance of the condition and willingness to receive information. The information need at each stage of their emotion would differ. Participants may also have felt compelled to give this source of information more positive scores due to a perceived association between it and the research. Also, this study does not take into account the impact of disease severity on amount of information needed and future studies should aim to address this; it is important to recognize that as the disease progresses, people's information needs may also change depending on their disability and burden of disease.

\section{Conclusion}

In conclusion, patients with newly diagnosed MS currently receive most information about their condition from the MS Society and MS specialist nurses. There is a general lack of information provided about optic neuritis. People with MS have identified that they wish to receive significantly more information from their general practitioners, eye specialists, neurologists, and education sessions.

\section{Practice implications}

More information needs to be provided to MS patients even at early stages of their disease. The biggest gap in information need related to the management of symptoms using optic neuritis as a model of management of symptom relapse. There is a general lack of information provided about optic neuritis from all information sources.

\section{Acknowledgments}

Dr Chen is supported by the Australian National Health and Medical Research Council (NHMRC) National Institute of Clinical Studies-Multiple Sclerosis Research Australia Betty Cuthbert Fellowship.

\section{Disclosure}

No conflicts of interest were declared in relation to this paper.

\section{References}

1. Somerset M, Sharp D. Campbell R. Multiple sclerosis and quality of life: a qualitative investigation. J Health Serv Res Policy. 2002;7:151-159.

2. Forbes A, While A, Taylor M. What people with multiple sclerosis perceive to be important to meeting their needs. JAdv Nurs. 2007;58:11-22.

3. Kersten P, McLellan DL, Gross-Paju K, et al. A questionnaire assessment of unmet needs for rehabilitation services and resources for people with multiple sclerosis: results of a pilot survey in five European countries. Clin Rehabil. 2000;14:42-49.

4. Somerset M, Campbell R, Sharp DJ, Peters TJ. What do people with MS want and expect from health-care services? Health Expect. 2001;4:29-37

5. Heesen C, Köpke S, Richter T, Kasper J. Shared decision making and self management in multiple sclerosis - a consequence of evidence. J Neurol. 2007;254 Suppl 2:II/116-II/121.

6. Vickrey BG, Shatin D, Wolf SM, et al. Management of multiple sclerosis across managed care and fee-for service systems. Neurology. 2000;55:1341-1349.

7. Box V, Hepworth M, Harrison J. Identifying information needs of people with multiple sclerosis. Nurs Times. 2003;99:32-36.

8. MacLean R, Russell A. Innovative ways of responding to the information needs of people with MS. Br J Nurs. 2005;14:754-757.

9. Arnold AC. Evolving management of optic neuritis and multiple sclerosis. Am J Ophthalmol. 2005;139:1101-1108.

10. Defriez M, Griffiths D, Millett C, Thakrar DN, Winterbotham M. The perception of the current provision of care for multiple sclerosis sufferers in the community. Prim Health Care Res Dev. 2003;4:233-243.

11. Forbes A, While A, Dyson L, Grocott T, Griffiths P. Impact of clinical nurse specialists in multiple sclerosis - synthesis of the evidence. $J A d v$ Nurs. 2003;42:442-462.
Patient Preference and Adherence

\section{Publish your work in this journal}

Patient Preference and Adherence is an international, peer-reviewed, open access journal that focusing on the growing importance of patient preference and adherence throughout the therapeutic continuum. Patient satisfaction, acceptability, quality of life, compliance, persistence and their role in developing new therapeutic modalities and compounds to

\section{Dovepress}

optimize clinical outcomes for existing disease states are major areas of interest. This journal has been accepted for indexing on PubMed Central. The manuscript management system is completely online and includes a very quick and fair peer-review system. Visit http://www.dovepress.com/ testimonials.php to read real quotes from published authors. 